\title{
WHERE AND WHY STUDENTS \\ CHOOSE TO USE COMPUTER \\ FACILITIES: A COLLABORATIVE \\ STUDY AT AN AUSTRALIAN AND \\ UNITED KINGDOM UNIVERSITY
}

\section{Liz Burke, Lea Beranek, Graham Walton and Ruth Stubbings}

The authors describe a collaborative study at two universities, one in Australia and the other in the UK. The main objectives of the study were to gain an understanding of the factors that influence a student's choice of location when using computing facilities, what applications they use, and how adequate various services and facilities provided by the two universities were.

AARL September 2008 vol 39 no3 pp181-197.

Lea G Beranek, Resource Delivery Services and Audiovisual Collection Development Librarian, Borchardt Library, La Trobe University, Melbourne 3086. E-mail: l.beranek@latrobe.edu.au. Liz Burke, Associate Librarian (Reader Services), University of Western Australia. E-mail: lburke@library.uwa. edu.au. Graham Walton, Ruth Stubbings, Library, Loughborough University. E-mails:J.G.Walton@lboro. ac.uk, R.E.Stubbings@lboro.ac.uk

\footnotetext{
A cademic libraries are undergoing significant change as more and more printed material becomes available electronically, as students demand collaborative and interactive study and learning spaces and as new technologies make possible things that were undreamt of previously. David Lewis notes:
} 
The changes that are necessary [to develop the academic library in 2025] will require libraries to be managed in different ways than has been the practice over the past 50 years. The culture in libraries, which dates from the 19th century practice, is based on carefully managed and controlled procedures and a conservative approach to change... The current challenges require different approaches and a different culture.'

One challenge for libraries is ensuring that any change to their services and facilities actually meets client need and is not merely a knee-jerk reaction to an assumed understanding of client need. Never before has there been a greater need to seek feedback directly from the library client.

Much has been written about the demands of the Net Generation ${ }^{2}$ and the need for new learning spaces that take advantage of all the latest technology and gadgets. While it is important to use such information when planning any changes to library services, it is also important that libraries survey their own client group and not rely solely on the findings of others' studies. In particular, knowing how its students decided where to use a computer and what applications they used could help the library in the planning of appropriate support and services.

To this end, the La Trobe University Library in Melbourne, Australia and the Loughborough University Library in Loughborough, UK, undertook a collaborative study to explore how students choose where to use a PC while on campus and how well each university was providing various services and facilities. The study assumed that, at both universities, the main places students used PCs were the Library, a faculty-provided computer lab, a centralised computer lab provided by the University IT/computer services unit, or their hall of residence. These assumptions were based on previous surveys conducted at both university libraries.

La Trobe University Library completed one such survey ${ }^{3}$ during September 2005. That survey measured some of the relevant parameters of online PC usage, confirmed peak-usage times, and determined the effect that 24 new PCs recently added to the network had on quality of service. A key finding was that clients waited in queues for access to an online PC for an average of 11 minutes during well-established peak-usage times, in spite of the additional 24 PCs. La Trobe Library also conducted a seating survey in 2006 which confirmed that during similar peak periods there were still substantial queues for the online PCs.

Loughborough Library conducted a use of space survey in $2006 .{ }^{5}$ Its purpose was to establish which learning spaces students used, why they used the space, and the levels of use. The key findings were that different types of learning space were highly valued by the students, that more PCs were needed in the Library, that more personal space was needed around some PCs and that the physical environment was paramount in choice of learning space. 


\section{THE LITERATURE}

In a study conducted in 1997, Lubans ${ }^{6}$ investigated what students were doing while using the computers in the library at Duke University in North Carolina. The study explored how male and female first-year students were using the Internet for academic purposes. Students were asked how often they used the Internet and about their skill level, how they stay current, their view of the library as a location to access the Internet, their comparative use of print and digital resources, and their expectations of librarians for helping them better use the Internet.

Since 2004 the EDUCAUSE Center for Applied Research has conducted annual studies into the use by undergraduate students of information technology. The 2007 study $^{7}$ found that $98.4 \%$ of the 27846 students who responded to the survey owned a PC and the average time spent online was 18 hours per week. Ownership of laptop PCs had increased by more than 7\% since the 2006 survey, to $74 \%$. Similar studies have been conducted by a number of universities in Australia. In an investigation into University of Melbourne first-year students' experience with technology, Kennedy, Judd, Churchward, Gray and Krause ${ }^{8}$ surveyed 2000 students in $\mathbf{2 0 0 6}$ on their access to, use of and preferences for an array of established and emerging technologies and technology based tools. While results showed that many first-year students were tech-savvy, there were areas where the use of and familiarity with technology-based tools were far from universal or uniform among first-year students. For a number of activities, the proportion of students who had never used a particular technology-based tool outstripped those who had. Examples of these activities were creating a website, keeping a blog, using RSS feeds or using a mobile phone to access the web.

A similar study of first-year students at the University of Western Australia was reported at the First Year in Higher Education Conference in Brisbane in 2007. Skene, Cluett and Hogan ${ }^{9}$ were concerned that much of the literature on today's university students emanates from North America and relates to student populations that can differ in significant ways from Australian student populations. They therefore surveyed first-year students in 2006 on their access to and use of information and communication technology. Their survey results revealed that access to the Internet was wide-spread, with $95 \%$ of students surveyed having Internet access at home and $90 \%$ of the students being online more than once a day. Portable devices were common, with $96 \%$ owning a mobile phone and $56 \%$ owning a laptop. Instant messaging was used by $46 \%$ at least once a day, $23 \%$ were blogging on a weekly basis, $74 \%$ downloaded music and $66 \%$ used YouTube.

Results of these types of studies revealed that students were spending a significant amount of time online and had high expectations of online services. These results make it clear that it is important that academic libraries monitor students' use of and need for PCs and access to the Internet. 


\section{PROJECT AIMS AND OBJECTIVES}

This collaborative study conducted by La Trobe and Loughborough Universities aimed to discover what factors influenced a student's choices for on-campus PC usage. The objectives included:

- exposing the factors and measuring their influence on students' choice of location when using a PC on campus;

- identifying the software applications used by students and whether this affected their 'choice of location' decision;

- gathering data that could be used to facilitate planning for both hardware and software provision and support; and

- comparing and contrasting the detailed usage of PCs by students in an Australian and a UK university environment.

This study also involved fostering collaboration between the two universities' centralised IT departments and the libraries. It also provided the opportunity for universities in different countries to collaborate with each other.

\section{METHODOLOGY}

This project was planned to be undertaken within existing workloads, with possibly no additional resources allocated. The challenge was, therefore, to collect meaningful data as efficiently as possible. Once the project was underway, the project teams at both universities received a small amount of funding to support the project.

The project was timetabled to take place between December 2005 and September 2006. A data collection protocol and questionnaire were developed by the project team. The actual timing of the data collection was left up to the individual universities, as the scheduling of the academic year is not the same in Australia and the UK. At La Trobe University, only the Bundoora Campus was involved, as it was decided that conducting the survey across a number of geographically disparate sites would add a level of complexity that the project team did not want to factor into their first experience of an international collaborative project. A set of core questions was used by each institution and some additional questions specific to each institution were also included.

The survey was promoted differently at both universities. At La Trobe University the retailers in the central square on campus were approached to donate spot prizes in return for promotion of their support during the survey. The response from retailers was enthusiastic and a variety of prizes were donated. Loughborough University Library had also found that incentives encouraged student participation. It was standard practice at Loughborough for respondents to be automatically placed in a prize draw for either printer credits or photocopy cards. This practice was followed for this survey and students who completed the questionnaire were entered into a prize draw for $£ 20$ worth of printer credits.

Loughborough University Library undertook a pilot of the survey questionnaire on behalf of both universities. Respondents were asked four questions: 
- Was the questionnaire easy to complete?

- Were there any questions which were unclear?

- Did the questionnaire allow you to express the views you have about accessing a $\mathrm{PC}$ on campus?

- Any other comments?

The information from the pilot indicated that the survey questionnaire did not require significant alteration. The pilot did, however, identify some ambiguity in the wording of a few questions which were changed accordingly.

The survey was administered at La Trobe University as a printed questionnaire from Monday 15 May to Friday 26 May 2006. Students were surveyed in seven locations:

- the Library

- the Computer Study Hall

- Engineering computer laboratory

- Health Sciences computer laboratory

- Law \& Management computer laboratory

- Humanities and Social Science computer laboratory

- Education computer laboratory.

The survey forms were colour-coded to assist in distinguishing responses from the various locations. The forms were distributed by casual staff employed by the Library and the total number of responses received was 757 .

At Loughborough University, the survey was administered from Monday 24 April to Sunday 30 April 2006, primarily electronically, but a printed version was available for completion in the Library. This was agreed after Computing Services and Departmental IT Laboratory staff indicated that paper distribution in their PC areas was not appropriate. An electronic version was made available to all registered students. Students responded from the following locations:

- Library

- Computing Services

- Engineering IT Laboratory

- Science IT Laboratory

- Social Science and Humanities IT Laboratory

- Other (Home and/or Hall of Residence).

Only one week was needed for data collection at Loughborough because of the very high response rate to the electronic questionnaire. Within seven days, 611 e-mailed responses were received. Eighty-three paper questionnaires were returned in the Library, giving a total number of 694 responses.

Building on their previous experiences, the members of the project team decided that the questionnaire would contain the following 12 key library performance criteria.

1. Opening hours

3. Range of software

5. Near to friends
2. Location

4. Print facilities

6. Physical environment 
Liz Burke et al
7. Close to resources
8. Availability of support
9. Immediate availability of PCs
10. Personal safety
II. Age of PCs
12. Cost of printing.

These criteria were ranked by each respondent's allocation of a level of importance as well as one for adequacy. The levels of importance used in the questionnaire were: Very Important, Important, Not Important. The levels of adequacy used were: Very Good, Good, Poor. All the survey data were entered into SPSS by a consultant employed by the Library at each institution. Cross-tabulations of the raw data were produced within SPSS and plotted as graphs of importance versus adequacy for each of the above criteria at each library. (Space does not permit these 3-D colour plots to be published here, but they are available on request from the authors.) Once the data were available, each institution analysed their own data and then comparisons across the two institutions were made.

\section{SURVEY RESULTS}

\section{Categories of Respondents}

Both institutions received a similar number of responses, 757 at La Trobe and 694 at Loughborough. The proportions surveyed at $\mathrm{La}$ Trobe corresponded closely with the overall University campus population, so the La Trobe project members were confident that the survey was not biased by over- or under-representation in these categories. The total responses at Loughborough represent $5.5 \%$ of the total University student population, which gave a reasonable level of confidence in the findings.

Graph 1: Categories of Respondents at La Trobe and Loughborough Universities

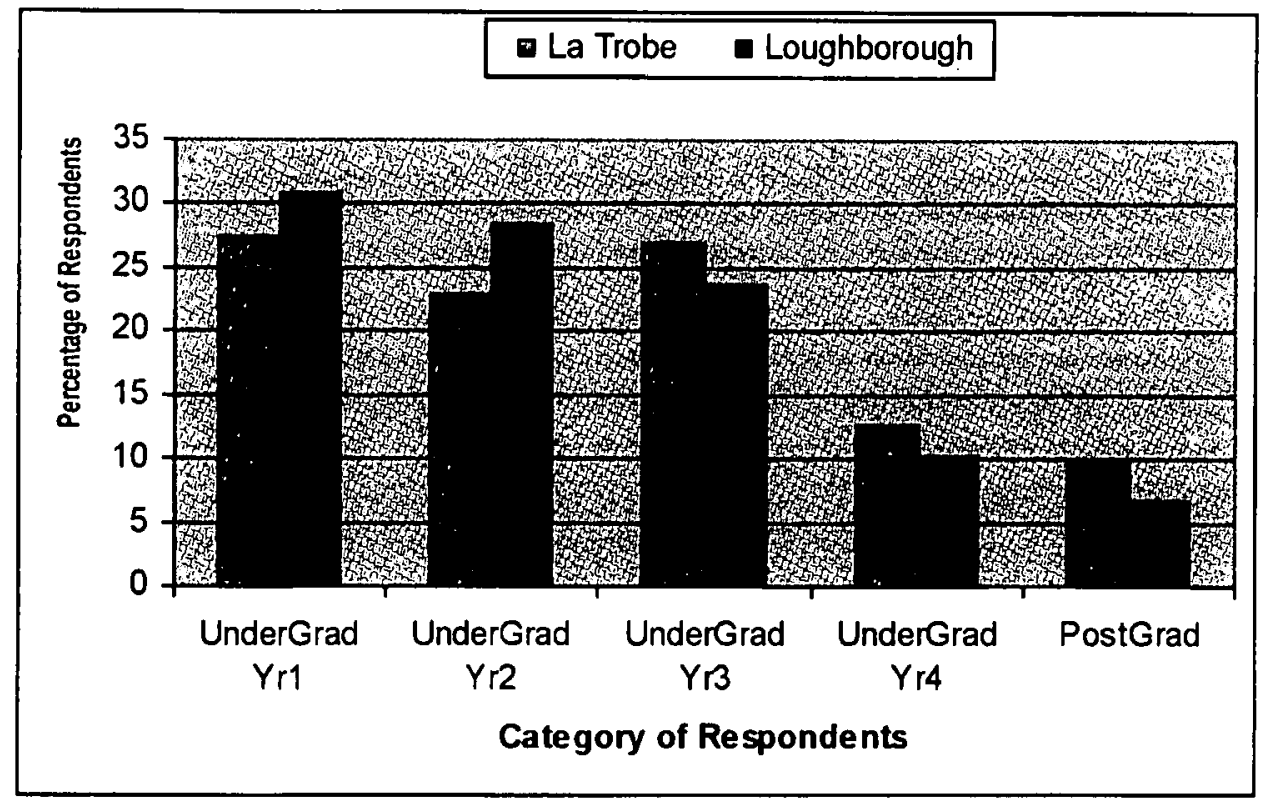


A high majority of respondents were full-time students at both universities, a result which did not surprise the project team.

\section{Location When Completing Survey}

Most respondents at La Trobe $(511,68 \%)$ were in the Library when they completed the questionnaire. The remaining $32 \%$ of respondents were evenly divided among the Computer Study Hall and Faculty laboratories. This applied equally to undergraduates and postgraduates. In fact, $59 \%$ of survey respondents noted their preferred location for using computing facilities was the Library. Fewer than $20 \%$ of all respondents said they used wireless network facilities and, of these, only $10 \%$ said they used this facility 'more than once a week'. Although these numbers appear small, they are expected to increase as wireless access expands on campus and more students acquire laptops. These results at La Trobe confirmed findings from previous surveys conducted by the Library.

At Loughborough, the majority of respondents $(423,61 \%)$ were in the location known as 'Other', which the project team believed to be hall of residence or home. Another difference was that La Trobe used a printed questionnaire, whereas the Loughborough questionnaire was primarily electronic. These factors may have affected how the questionnaire was completed. With so many Loughborough students filling in the electronic version in hall/home it may be that it was done as part of dealing with their e-mails (social or otherwise), and these students may use their hall/home PCs on a regular basis for all tasks.

Graph 2: Location of all Respondents When Completing the Survey

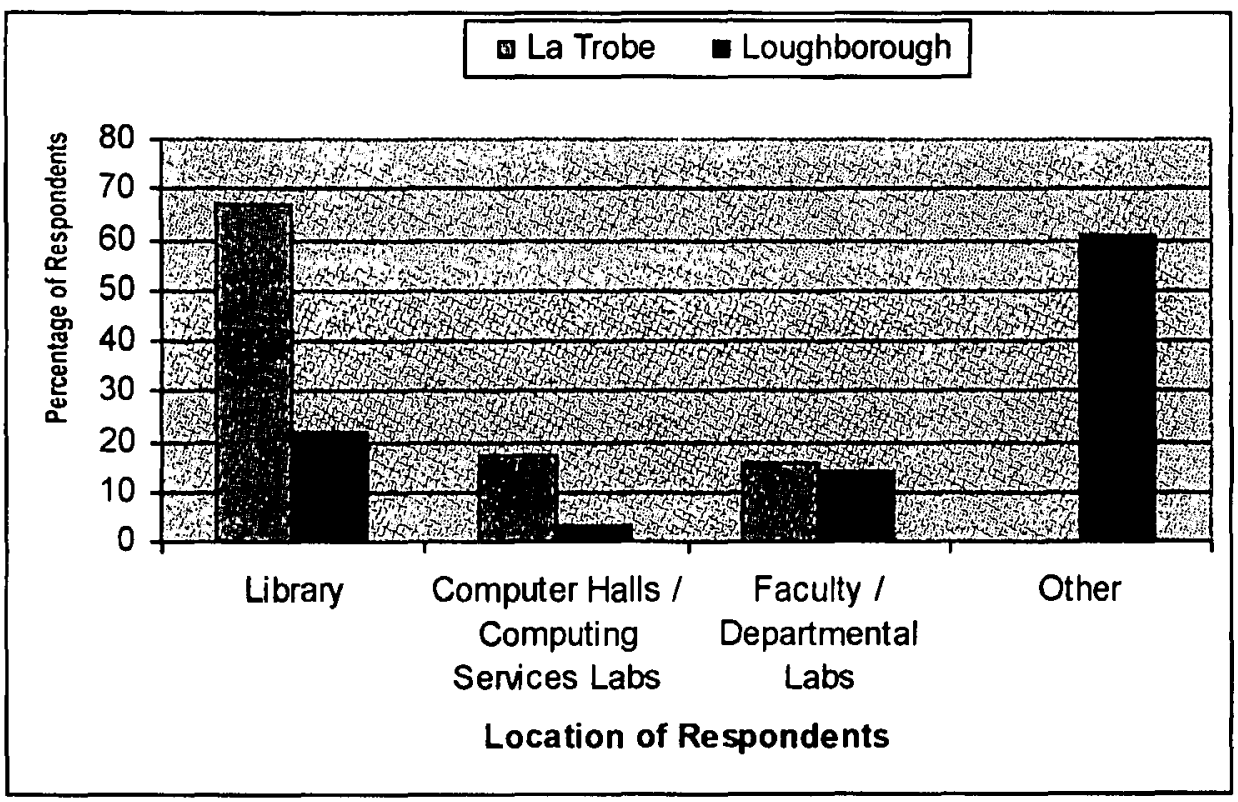




\section{Frequency of Using Computing Facilities}

Graph 3 shows that at La Trobe University, over $67 \%$ of respondents said they used the PCs in the Library more frequently than once a week. These responses were nearly equally distributed between 'Several Times a Day', 'Once a Day' and 'More than Once a Week'. Not shown in Graph 3 is that $55 \%(416)$ of respondents never used PCs in the Computer Study Hall and, of the rest, more than half used the facility more frequently than once a week.

PCs in Faculty laboratories were never used by approximately half the respondents $51 \%$ (392). More than half the respondents who used them did so more often than once a week. However, compared to the results from the other locations, there was a higher proportion using the Computer Study Hall just once a week. Respondents indicated that $58 \%$ (438) never used computing facilities in home/ halls of residence and, of the ones who did, more than $75 \%$ used them more often than once a week. Fewer than 20\% (133) of respondents used wireless network facilities, and of these, just $10 \%$ (83) used this facility more often than once a week. Wireless access was available in the library at the time of the survey and was also being rolled-out across the campus.

Graph 3 shows that $29 \%$ (194) of Loughborough respondents said they used the PCs in the Library more frequently than once a week. Not shown in Graph 3 is that PCs were used 'Several Times a Day' in the University hall of residence and at home by $83 \%(567)$ of respondents. This increased to $92 \%(629)$ when the time period wass extended to at least weekly. In the Departmental laboratories, $41 \%$ (276) of respondents used PGs at least weekly.

\section{Graph 3: Comparison Between Institutions of Frequency of Use of PCs in the Library}

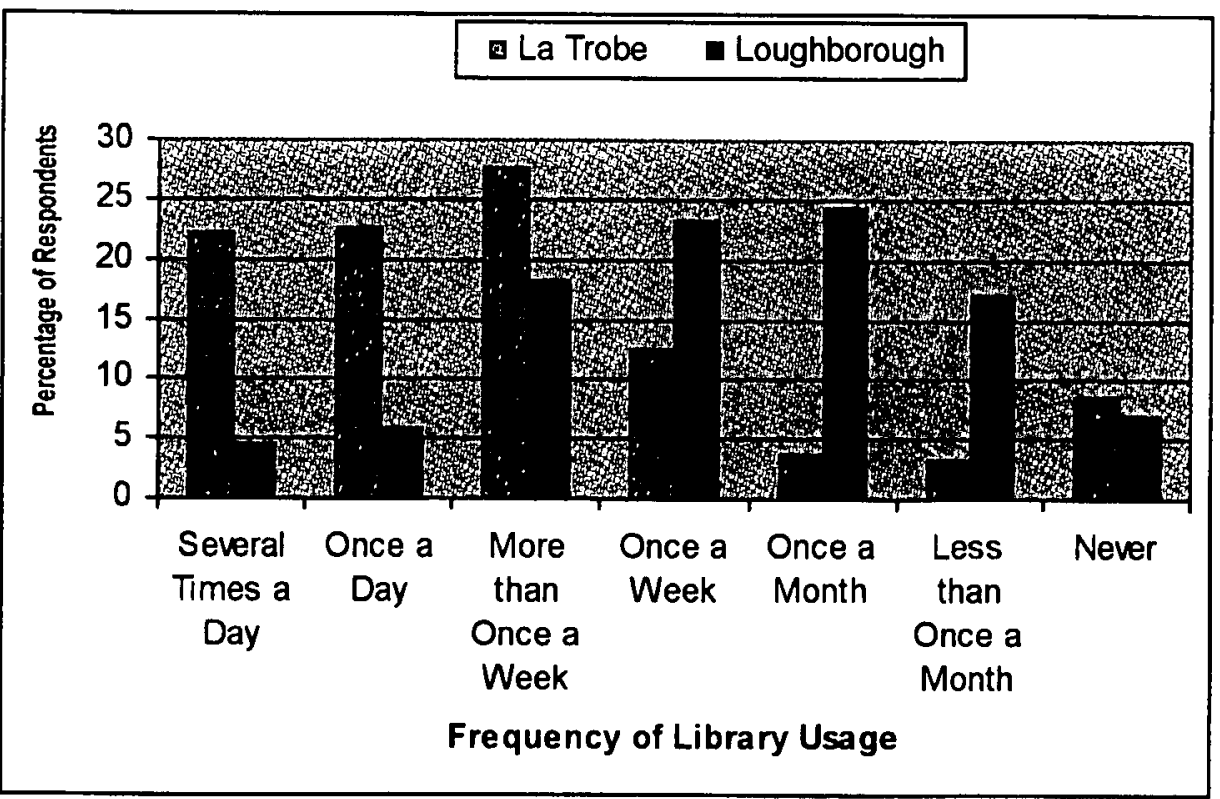




\section{Importance Criteria for Preferred Location}

At La Trobe it was evident that for all locations, 'immediate availability of PCs' and 'print facilities' were the most important criteria (75\% or higher) for respondents and that 'near to friends' was ranked as 'not important' (see Graph 4). For the Library, five other criteria were also regarded as 'very important' by about half of the respondents. These were 'location' (60\%), 'close to resources' (59\%), 'cost of printing' (59\%), 'opening hours' (55\%) and 'physical environment' (49\%). For the Computer Study Hall, at least half of the respondents regarded three other criteria as 'very important'. These were, 'opening hours' (57\%), 'physical environment' (54\%), and 'cost of printing' (54\%). For the Faculty laboratories, at least half of the respondents regarded two other criteria as 'very important': 'opening hours' (58\%) and 'physical environment' (57\%).

\section{Graph 4: Relative Importance of Criteria for Choosing Where to Use a PC at La Trobe}

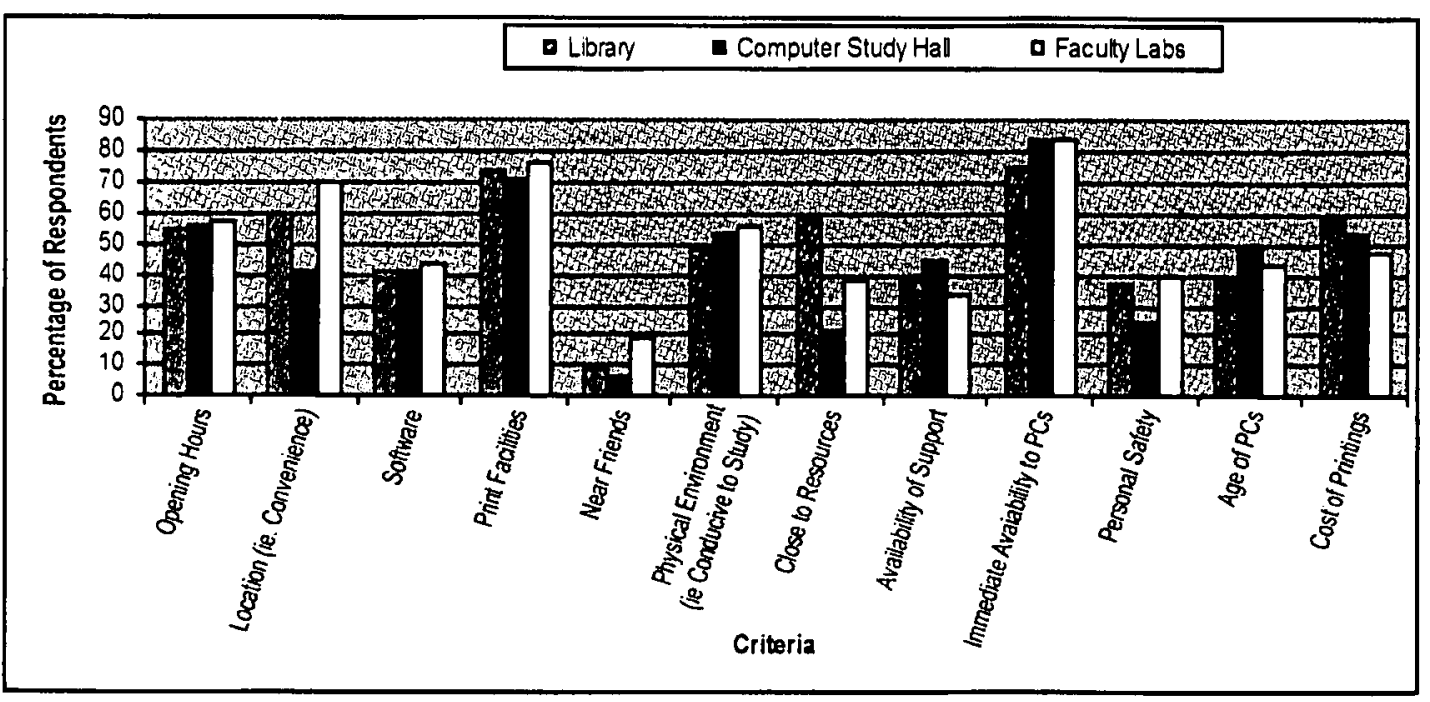

At Loughborough, respondents seemed to value different selection criteria for each location (see Graph 5). It was also interesting to note that Loughborough respondents valued least for all locations the opportunity to work near friends, availability of support and personal safety. 
Graph 5: Relative Importance of Criteria for Choosing Where to Use a PC at Loughborough

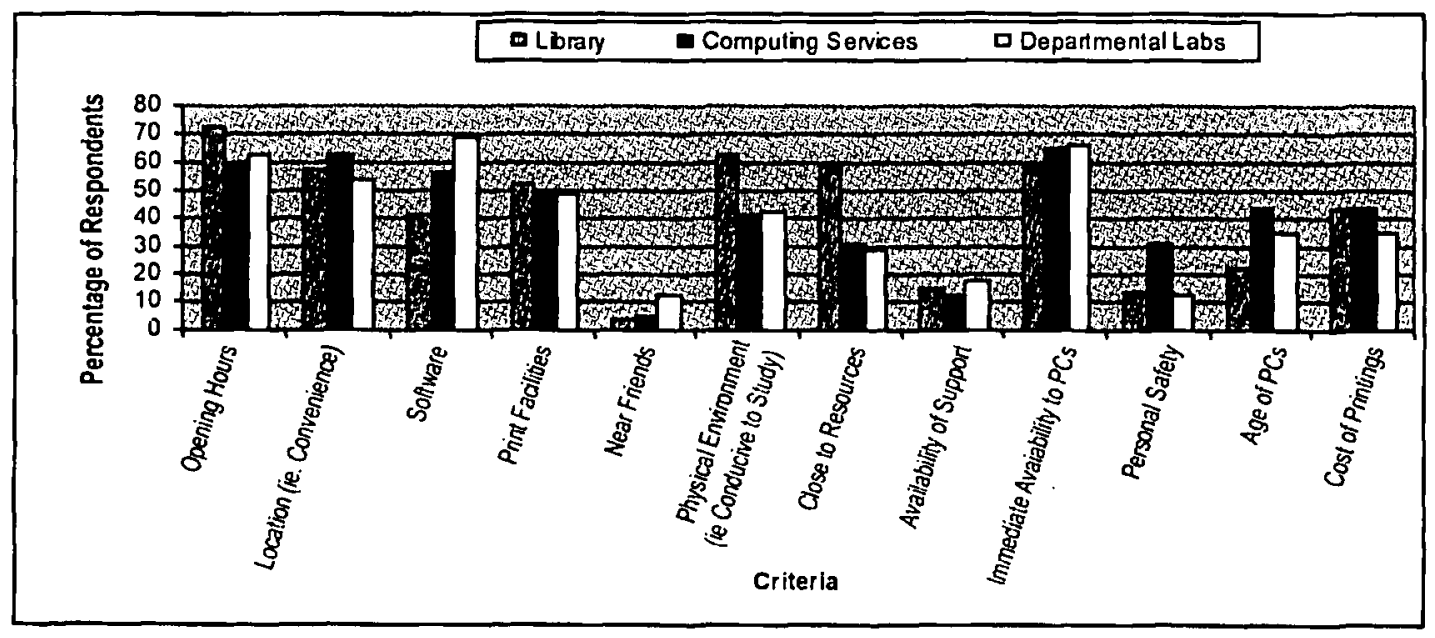

Availability of PCs and opening hours were established as being of high importance across all three locations: the Library, Computer Study Hall/Computer Services and Faculty laboratories/ Departmental laboratories at both universities.

\section{Perceived Adequacy of Various Services and Facilities}

Adequacy was indicated by the survey respondents as 'very good', 'good' or 'poor' for each of the 12 services/facilities provided by the two universities. This simple ranking scheme's numerical results were then cross-tabulated with the students' responses to the question about importance of each of the twelve services/ facilities, thus linking adequacy with importance. This gave a richer gradation of steps (from 'very good AND very important' to 'poor AND not important'). It also permitted a more meaningful interpretation of the students' responses when 'adequacy' and 'importance' were combined. The best performance ratings for each criterion varied considerably from location to location, although the 'cost of printing' was the lowest rated criterion for all locations.

At La Trobe, many students rated the Library as 'very good' at providing a number of services/facilities. In decreasing order, these were: $56 \%$ of respondents said the 'location (i.e. convenience)' was 'very good', $52 \%$ said that computing facilities 'close to resources' was 'very good', and $49 \%$ indicated the Library's 'opening hours' were 'very good' (see Graph 6). For the Computer Study Hall, $53 \%$ of respondents indicated 'opening hours' were 'very good' and a further $40 \%$ of respondents indicated they were 'good'. Other facilities and services that respondents gave a 'very good' rating were 'print facilities', 'availability of support' and 'age of computer'. A very high percentage of respondents (73\%) gave the Computer Study Hall a 'good' rating for providing computing facilities 'close to friends'. For Faculty laboratories, $67 \%$ of respondents rated the provision of computing facilities in a convenient location as 'very good' and a further $32 \%$ indicated their location was 'good'. The 'age of computers' also rated relatively 
well, with $59 \%$ of respondents saying this was 'very good' and a further $38 \%$ saying this was 'good'. As with the Library and the Computer Study Hall, 20\% of respondents rated the 'immediate availability of computer facilities' as 'poor'. Neither 'Close to resources' nor 'availability of support' rated well, with $15 \%$ and $17 \%$ respectively indicating these facilities were 'poor'.

Graph 6: Perceived Adequacy of Services and Facilities Provided at La Trobe

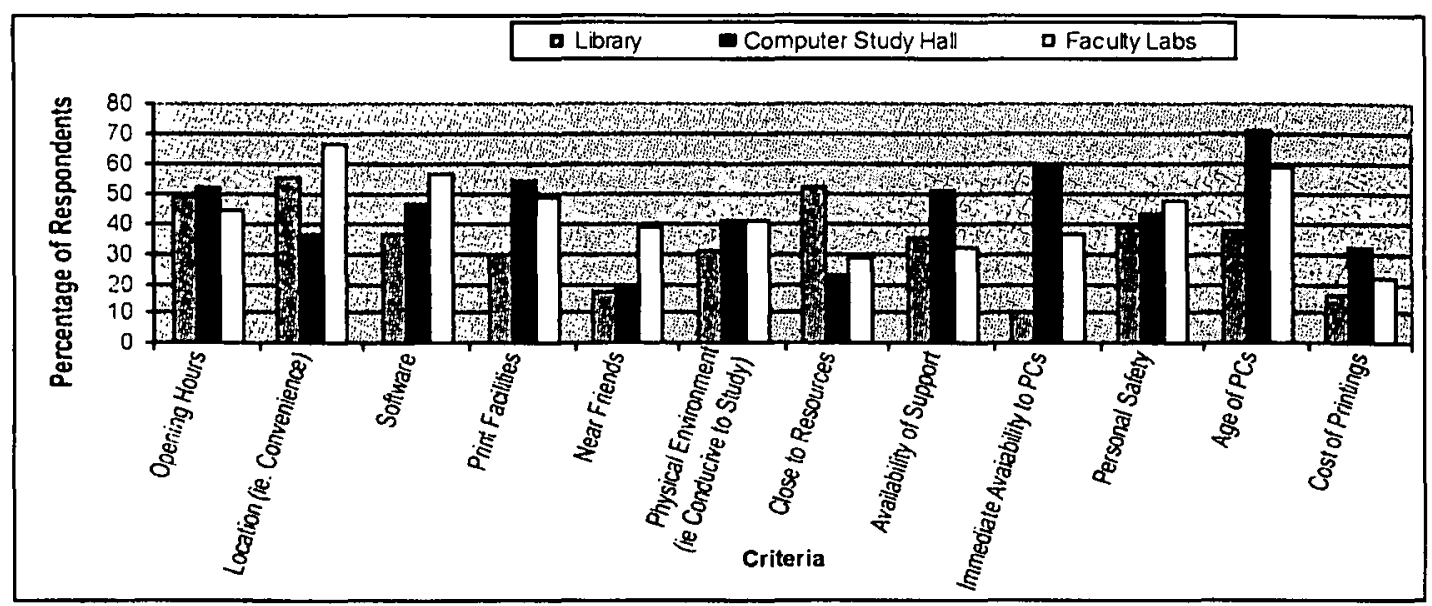

Graph 7: Perceived Adequacy of Services and Facilities Provided at Loughborough



At Loughborough, respondents were least happy with the cost of printing on campus followed by having PC facilities near to friends (see Graph 7). This was reflected by the comments received on the survey forms. Over 38 comments related to either the cost of printing, the inconvenience of where the printer kiosks were located or the quality of the printer service on offer: for example, 'Printing bit too expensive', 'there needs to be a better way of buying printer credits' and 'the printers are always low on toner'. 
The Library did not score as well against the Computing Services and Departmental laboratories in relation to opening hours, location, and immediate availability of PCs, age of PCs and provision of specialist software. Only $13 \%$ indicated that there was good availability of PCs. Where the Library specifically performed well was being close to other learning resources when using a PC $(70 \%)$. The Library was also rated comparatively highly for its physical environment (44\%) and support provided (35\%). It was not highly rated for access to software (32\%). The Computing Services labs achieved the highest rating for both the age of their PCs $(58 \%)$ and the range of software $(53 \%)$. This same highest rating was received for the immediacy that $\mathrm{PCs}$ were available $(50 \%)$. They were ranked the lowest for the print facilities (22\%). The Departmental laboratories were rated the highest for their opening hours (73\%) and their location (49\%). They were seen as being of lower quality than the Library or the Computing Services laboratories for the support provided and personal safety.

\section{Applications Used in Preferred Locations}

At both universities, the top three applications being used were 'Internet', 'e-mail' and 'Microsoft Office' (see Graph 8).

Graph 8: Applications Used Very Often in Both Libraries

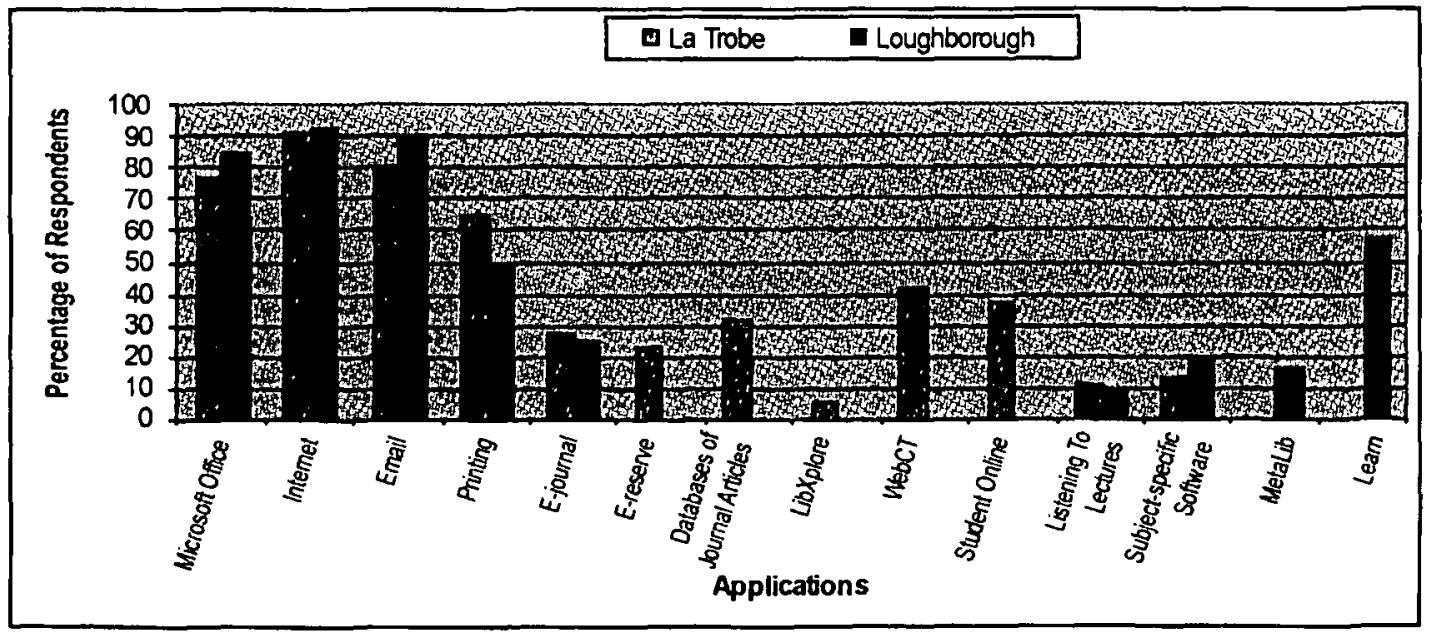

In the Library at La Trobe $92 \%$ of respondents indicated they used the Internet 'very often', with $81 \%$ for e-mail, $78 \%$ for Microsoft Office, and $66 \%$ for 'printing'. The most infrequently used applications were LibXplore (the Library's metasearching service) with $63 \%$ of respondents reporting that they 'never' used this facility, and 'Listening to Lectures', with 59\% reporting they 'never' used this facility. Use of e-journals was also relatively low, with $26 \%$ of respondents reporting that they 'never' used this facility, and with $20 \%$ of respondents reporting that they 'never' used E-Reserve. In the Computer Study Hall, Microsoft. Office, Internet, e-mail and printing facilities were the most used applications, with only $4 \%$ of respondents indicating they never used these 
applications. In the Faculty laboratories, Microsoft Office, Internet, e-mail and printing facilities were the most used applications, with only $7 \%$ of respondents indicating they never used these applications. Most respondents who preferred their Faculty laboratory indicated that they used these applications very often, ranging from $96 \%$ for Internet down to $65 \%$ for printing.

At Loughborough the top four applications in all locations, including hall of residence/home, used 'Very often' were the Internet, e-mail, Microsoft Office and Learn (the university's virtual learning environment). Listening to Lectures, e-journals and MetaLib (the Library's gateway to electronic resources) were the least used applications. Some slight variances did occur in the ICT applications used more heavily than others across the four areas (Library, Computing Services, Departmental labs, hall/home). The Internet was accessed by $94 \%$ of users in the Library, $100 \%$ in Computing Services, $97 \%$ in Departmental lab and $98 \%$ in hally home. With e-mail, $91 \%$ were in the Library, $94 \%$ in Computing Services, $97 \%$ in Departmental labs and $96 \%$ in hall/home.

In the Loughborough Computer Services laboratories, the Internet, e-mail and Microsoft Office were the most frequently used applications. These were followed by subject-specific software and printing. The least used applications were Listening to Lectures, with $74 \%$ respondents stating they never used the application, followed by e-journals with $46 \%$ and MetaLib with $38 \%$. In the Department laboratories, e-mail was the most frequently used application, with respondents stating that they used the facility very often. The next most popular application was the Internet, followed by Microsoft Office and Learn. The least popular applications, with respondents stating they never used the applications, were Listening to Lectures (79\%), MetaLib (35\%) and e-journals (33\%). Being able to access some specialist software only in departmental laboratories was a barrier for some students. In hall of residence/home, the most frequently used applications were, once again, Internet (98\%), e-mail (96\%), Microsoft Office (71\%) and Learn (39\%). The least popular applications were also repeated, with Listening to Lectures (69\%), MetaLib (41\%) and e-journals never being used by $30 \%$ of respondents.

At Loughborough Microsoft Office was used by $85 \%$ in the Library, $78 \%$ in Computing Services, $78 \%$, in departmental labs and by $71 \%$ at hall/home. Eresources (e-journals, MetaLib and Listening to Lectures) were the applications used the least across the locations.

\section{Cross-Tabulated Data}

The Library at La Trobe outranked all other locations as the preferred place to use computer facilities. This applied equally to both postgraduates and undergraduates. The provision of 'immediate access to PCs' in the Library was ranked by students as the 'most important' of all the services/facilities, other than 'printing facilities'. Unfortunately, it had by far the highest count of 'poor' adequacy, as well as the lowest percentage response in the 'Very Important + Very Good' category. These data indicated an ongoing and serious problem for the Library, which is currently being addressed. The availability of 'printing 
facilities' in the Library had the highest of all counts in the 'Very Important + Good' category. However, its 'poor' rating was the third highest of all services/ facilities and, therefore, signals a potential problem. Data suggested that students were close to maximally satisfied with the 'location' of the Library and the 'Closeness to resources'. The 'cost of printing' was the most specific of all the services/facilities and had the second highest 'poor' rating total as well as the second highest count for the 'Very Important + Poor' category across all services/facilities. This was very significant and indicated a high dissatisfaction level. In the Library, the 'availability of support' had the highest single count of 'Important + Good' of all the services/facilities.

For the Loughborough Library, the 'physical environment' (64\%) and 'location' (58\%) were considered to be important criteria for choosing to use a PC there. For the Computing Services laboratories, 'location' (63\%) was identified as being important and for the Departmental laboratories, the 'availability of software' (70\%) was the factor identified as being important, along with the PC availability and opening hours.

Across all three locations at Loughborough, students were least happy with the cost of printing. They also appeared to be discontented about how close to friends they were when accessing a PC. The Library did not score as well against the Computing Services and Departmental laboratories in relation to opening hours, location, immediate availability of PCs, age of PCs and provision of specialist software. Only $13 \%$ indicated that there was good availability of PCs in the Library. In the Library, applications that rated the highest in frequency of use were the Internet with $94 \%$ and e-mail, with $91 \%$ of respondents indicating they used these applications very often.

\section{Summary of Results}

The following are similarities deduced from the survey data, which apply equally well for both La Trobe and Loughborough Universities:

1. Students expected to have immediate access to a PC whenever they needed.

2. Students needed access to a $\mathbf{P C}$ as individuals more often than as part of a group.

3. Internet, Microsoft Office and e-mail were the heaviest used applications.

4. Students perceived that printing was too expensive on campus.

5. Depending on location of PC access, there were different ratings for what was considered to be most important as well as adequate.

6. Some students considered it restrictive to have access to specialist software only in departmental labs. 
The following differences were evident between the two universities:

1. Most respondents at La Trobe were in the Library when they completed the questionnaire. This is consistent with the survey showing the very high general rating of the Library as 'the preferred place for study'.

2. At Loughborough most respondents were in locations identified as 'Other', which the project team believed were hall of residence or home. This may have affected how the questionnaire was completed.

3. Loughborough's use of electronic questionnaires via e-mail was a very efficient technique, halving the survey administration time compared to the paper method of La Trobe. Unfortunately, this difference makes the direct comparison of some of the results difficult.

\section{DISCUSSION}

The project highlighted that students want greater access to PCs, lower printing costs and more printers. This finding was disappointing for La Trobe, as the Library has been consistently increasing the number of PCs and printers over several years. Despite these inadequacies, the Library at La Trobe outranked all other locations as the preferred place to use computer facilities, possibly because of the perception that the Library is working hard to satisfy the increasing computing needs of students. Clearly these problems are ongoing and the library has planned to further increase the number of PCs, wireless access to accommodate laptop usage and printers in the short-term. In the medium to long term, the projection of student usage of mobile phones with Internet access should alleviate the need for large numbers of $\mathrm{PCs}$ in libraries or computer barns.

The excessive 'cost of printing' at both universities continues to be a problem. A possible solution could be to incorporate these costs in an alternative revenue stream other than the current user-pays scheme.

Students did not appear to use electronic information resources subscribed to by the libraries very heavily. This could have been because students have a low level of awareness of the available electronic resources. It was also interesting to note that the Internet was much more heavily used than other e-resources applications, such as e-books and e-journals. Students could have been using ebooks or e-journals but categorised them under the broad heading of 'Internet'. However, this was not explored in great detail. Further investigation into this area would be relevant and appropriate.

It was interesting to note that, at both universities, respondents valued least for all locations the opportunity to work near friends, availability of support and personal safety. This was surprising to the project members, who had believed that the Library provided added value in terms of a group-working PC environment and availability of face-to-face support. The low priority of personal safety could be attributed to the campus giving students a sense of personal security. The low priority of being near friends could indicate that PC use is primarily done individually and not as part of a group. 


\section{CONCLUSION}

The study aimed to discover what factors influenced a student's choice of location when using a computer on campus, to identify the computer applications used by students and whether this had any effect on their 'choice of location' decision, to gather other data that can be used to facilitate planning for computer provision and support, and to explore the differences and similarities experienced by the two universities in conducting the project. All these objectives were met.

Results of the study highlighted some areas which would benefit from additional research, such as students' perceptions of library-subscribed e-resources versus the Internet. Survey results also provided a rich source of student feedback to assist both university libraries to continue planning appropriate services and facilities for their respective client groups.

It is a credit to the two universities and the project team that the levels of complexity across two universities in two countries did not prevent the project from succeeding.

\section{Acknowledgment}

The authors would like to thank the anonymous referees for their helpful comments.

\section{NOTES}

1. David W Lewis 'A Model for Academic Libraries 2005 to 2025' Paper presented at Visions of Change, California State University at Sacramento 26 January 2007.

2. J Hartman, P Moskal \& C Dziuban 'Preparing the Academy of Today for the Learner of Tomorrow' in D G Oblinger \& J L Oblinger (eds) Educating the Net Generation, EDUCAUSE 2005 at http://www.educause.edu/ EducatingtheNetGeneration/5989 viewed 25 September 2007; A H Moore, J F Moore \& S B Fowler 'Faculty Development for the Net Generation' in Oblinger \& Oblinger op cit; K Crawford Adult Themes Sydney Macmillan Australia 2006.

3. Lea G Beranek 'A Method of Predicting Queuing at Library Online PCs' Australian Academic \& Research Libraries v 37 no 42006 pp260-272.

4. La Trobe University Library 'Bundoora Seating Usage Survey 2006' at http://www.lib.latrobe.edu.au/about/surveys/seatingsurvey2006.pdf viewed 22 August 2007.

5. Graham Walton 'Learners' Demands and Expectations for Space in a University Library: Outcomes from a Survey at Loughborough University' New Review of Academic Librarianship v 12 no 22006 pp 133-149.

6. J Lubans 'How First-year University Students Use and Regard Internet Resources' at 2005 http://www.lubans.org/john.html viewed 15 April 2005. 
7. J Borreson Caruso \& G Salaway 'The ECAR Study of Undergraduate Students and Information Technology 2007: Key Findings' EDUCAUSE Center for Applied Research at http:/www.educause.edu/ir/library/pdf ERS0706/ekf0706.pdf viewed 25 September, 2007.

8. G E Kennedy, T S Judd, A Churchward, K Gray \& K-L Krause 'First Year Students' Experiences with Technology: Are They Really Digital Natives?' Australasian Journal of Educational Technology vol 24 no 12008 pp $108-122$ at http://www.ascilite.org.au/ajet/ajet24/kennedy.html viewed 15 February 2008.

9. J Skene, L Cluett \& J Hogan 'Engaging Gen Y students at University: What Web Tools do they Have, How do They Use Them and What do they Want?' Paper presented at First Year in Higher Education Conference, Brisbane, 2007 at http://www.studentservices.uwa.edu.au/ss/learning/ networking_smarter/llrs_projects/llrs_publications_list?f $=173438$ viewed 29 August 2007. 